\title{
Research Article Effect of Process Parameters on Gas Nitriding of Grey Cast Iron
}

\author{
Nana Wang and Jinxiang Liu \\ School of Mechanical Engineering, Beijing Institute of Technology, Beijing 100081, China \\ Correspondence should be addressed to Jinxiang Liu; liujx@bit.edu.cn
}

Received 2 August 2013; Revised 22 October 2013; Accepted 18 November 2013

Academic Editor: Martha Guerrero

Copyright (C) 2013 N. Wang and J. Liu. This is an open access article distributed under the Creative Commons Attribution License, which permits unrestricted use, distribution, and reproduction in any medium, provided the original work is properly cited.

\begin{abstract}
Gas nitriding process parameters have significant effects on the nitriding layer of material. In the present work, a series of gas nitriding experiments on pearlitic grey cast iron specimens were carried out at different temperatures. To study the influence of nitriding process parameters on the nitriding layer, the numerical simulations of nitriding processing are performed, which take into account the threshold value of nitriding potential. The results show that the numerical simulations, incorporating the nitriding potential's threshold value, can accurately predict the case depth and nitrogen concentration profile. The nitriding layer increases with increasing nitriding time and temperature, whereas the nitrogen concentration on the surface decreases with increasing temperature. Besides, the results also reveal that the nitriding potential nearly has no effect on the case depth, whereas it has great influence on nitrogen concentration on the surface and chemical composition of the compound layer.
\end{abstract}

\section{Introduction}

Gas nitriding is a typical thermochemical surface treatment within the eutectoid temperature, in which the nitrogen is transferred from the ammonia gas into the workpiece surface, generating the gamma phase $\left(\gamma^{\prime}-\mathrm{Fe}_{4} \mathrm{~N}\right)$ and epsilon phase $(\varepsilon-$ $\left.\mathrm{Fe}_{3} \mathrm{~N}\right)[1,2]$. After nitriding, the so-called compound layer and diffusion zone can be formed, which are capable of improving the wear and corrosion resistance of materials and enhancing the fatigue endurance $[3,4]$, respectively. The nitriding process parameters, such as nitriding time, nitriding temperature, and nitriding potential, have great influence on the forming of nitriding layer. The nitriding process parameters are mainly determined by experience in practical engineering applications. Their effects on nitriding layer are not very clear from a mathematical view. Therefore, considering the sensitivity of nitriding layer to the process parameters, there is an urgent demand to investigate the influence of the process parameters mathematically.

In recent years, a significant amount of experimental work has been conducted, aiming to investigate the nitriding process parameters' effect on nitriding process. Nevertheless, due to high time-consuming and economic costs, the experimental method is not very effective and feasible in practical applications, especially when the parameters vary in a wide range. Under the circumstances, numerical analysis can be a good choice to study the processing parameters' influence. Arif et al. [5] investigated the effect of nitriding time, nitriding temperature, and nitriding potential on the nitrogen concentration and hardness depth profile by using finite element code. In their research, the influence of the compound layer on the nitrogen concentration distribution was not considered, so the calculated case depth was larger than the experimental data. To avoid the aforementioned shortcomings, Yang et al. [6, 7] proposed a compound layer growth model for an alloy steel. However, the difference between the critical value and threshold value of nitriding potential was ignored in Yang's research. Besides, Hu et al. [8, 9] simulated the nitriding process under multistage nitriding potential controlling. In their study, a nitriding layer without the compound layer was obtained by controlling nitriding process parameters. Furthermore, most of the researches published in the literature were focused on the nitriding process of pure iron or steels. For grey cast iron, a widely used material, related studies are lacking.

In the present work, a series of gas nitriding experiments on grey cast iron specimens were conducted at 550, 570, and $590^{\circ} \mathrm{C}$. Afterwards, the numerical simulations were performed, which combined the influence of nitriding potential's threshold value on nitriding layer and Fick's second law. The 
calculated thickness of diffusion zone was compared with the tested data to verify the numerical simulations. Finally, the effect of nitriding process parameters, including nitriding temperature, nitriding potential, and nitriding time, was further investigated.

\section{Experimental Work}

2.1. Material. The material tested in the study is pearlitic grey cast iron. The chemical composition of the material is shown in Table 1. Figure 1 depicts the microstructure of the grey cast iron. The graphite within the material is in a sheet form. Due to the large amount of graphite, the grey cast iron has good heat transfer ability, self-lubricating performance, and good casting property. It is a very suitable material for components operating under high temperature and friction condition.

\subsection{Nitriding Process, Sample Preparation, and Equipment.} Gas nitriding experiments were carried out on grey cast iron specimens. The specimens were divided into three groups, with two specimens in each group. The tested temperatures were set as 550,570 , and $590^{\circ} \mathrm{C}$ for each group, with the same total time of 24 hours and nitriding potential of $1.5 \mathrm{~atm}^{-1 / 2}$.

After nitriding, the specimens were prepared by a standard grinding and polishing procedure, and microstructure observation was performed using JSM-5610LV SEM. Specimens were etched by $5 \%$ Nital in order to observe the nitriding layer by OLYMPUS PMG3. Hardness of the samples was also tested by applying a load of $1 \mathrm{~N}$ with holding time of $10 \mathrm{~s}$. Besides, the hardness tests were conducted in 6 points of one sample and the average value was taken to represent the final hardness.

In order to obtain the composition of the nitriding layer, XRD analysis of the surface layer was performed using D8 ADVANCE X-ray diffractometer with $\mathrm{CuK}$, at $40 \mathrm{kV}$ and $40 \mathrm{~mA}$. The scanned area was in the range of $15-90^{\circ}$.

\section{Numerical Model of Gas Nitriding Process}

3.1. Theoretical Background. In gas nitriding, the atomic nitrogen is dissociated from ammonia $\left(\mathrm{NH}_{3}\right)$ gas and then diffuses into the workpiece surface of component. The dissociation obeys the following rule:

$$
\mathrm{NH}_{3}=\frac{3}{2} \mathrm{H}_{2}+[\mathrm{N}]
$$

where $[\mathrm{N}]$ represents $\mathrm{N}$ atom dissolved in the workpiece surface.

The above equation presumes that equilibrium has been established. The activated atomic nitrogen is dissolved in the iron crystal lattices, which not only promotes the nitriding of $\alpha$-Fe, but also accelerates the formation and growth of compound layer. The solution of atomic nitrogen in pure iron is relatively fast, which does not affect the nitriding rate [10]. When building numerical model, for convenience, it is assumed that the graphite has no influence on the nitriding rate, although graphite is widely distributed in the iron matrix [11]. The resulting effect of this assumption will be discussed in detail in Section 5.1.

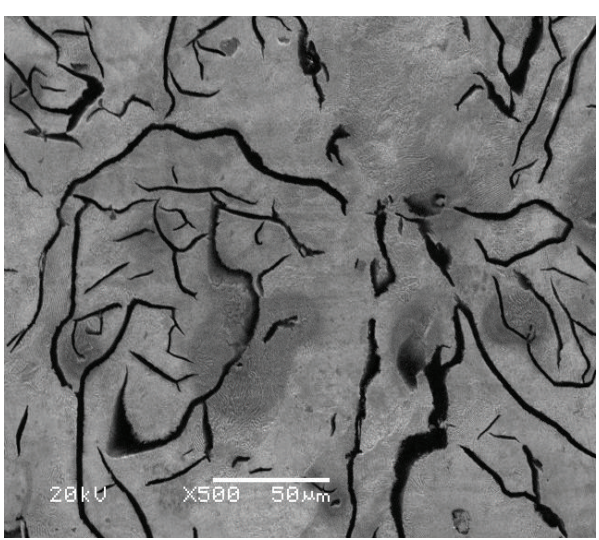

FIGURE 1: SEM analysis of the grey cast iron used in an engine cylinder liner.

The transformation of atomic nitrogen within grey cast iron is determined by the diffusion velocity, which is described by Fick's second law:

$$
\frac{\partial c}{\partial t}=D \frac{\partial^{2} c}{\partial x^{2}}
$$

where $c$ represents the nitrogen concentration within the material and $D$ is the diffusion coefficient of atomic nitrogen.

3.2. Numerical Model and Boundary Conditions. Nitriding potential is the measurement of nitriding ability of $\mathrm{NH}_{3}$ gas. The phases and nitrogen concentration on the nitriding surface are closely related to the nitriding potential after local equilibrium is established. At the earliest, the well-known Lehrer diagram of pure iron, which was constructed by Lehrer through investigating the equilibrium conditions of $\mathrm{NH}_{3}-\mathrm{H}_{2}$ and $\mathrm{Fe}-\mathrm{N}$ [12], was used to determine the relationship of the nitrided phases, nitrogen concentration, and nitriding potential.

The critical value of nitriding potential is defined as the turning point when the nucleation of $\gamma^{\prime}$ phase occurs at certain temperature. This value can be directly obtained from the Lehrer diagram. However, in engineering applications, the nitriding potential for compound layer nucleation is not completely equal to the critical value, since a minimal value, the so-called threshold value, has to be exceeded for certain nitriding time. The theoretical equation [13] for threshold value of nitriding potential is

$$
K_{\mathrm{nt}}=\frac{K_{\mathrm{nc}}}{1-\exp \left(\beta^{2} t / D\right) \operatorname{erfc}(\beta \sqrt{t} / \sqrt{D})},
$$

where $K_{\mathrm{nt}}$ is the threshold value of nitriding potential for nitriding time $t, K_{\mathrm{nc}}$ is the critical value of nitriding potential, $\beta$ is the mass transfer coefficient in gas-solid reaction, and erfc represents the complementary error function.

At a certain nitriding temperature, the time $t_{c}$, representing the nucleation starting time of compound layer, can be obtained by substituting the critical value of nitriding potential into (3). For accuracy, a two-stage process is defined 
TABLE 1: Chemical composition (wt.\%) of the studied grey cast iron.

\begin{tabular}{lcccccccccccccc}
\hline $\mathrm{C}$ & $\mathrm{S}$ & $\mathrm{Si}$ & $\mathrm{P}$ & $\mathrm{Mn}$ & $\mathrm{Cr}$ & $\mathrm{B}$ & $\mathrm{Cu}$ & $\mathrm{Ni}$ & $\mathrm{Ti}$ & $\mathrm{V}$ & $\mathrm{Mo}$ & $\mathrm{Nb}$ & $\mathrm{Fe}$ \\
\hline 2.98 & 0.032 & 1.646 & 0.061 & 0.469 & 0.051 & 0.003 & 0.348 & 1.278 & 0.045 & 0.042 & 0.874 & 0.066 & $\mathrm{Bal}$. \\
\hline
\end{tabular}

in the current study. In the first stage, that is, $t \leq t_{c}$, the compound layer is not formed. In the second stage, that is $t>t_{c}$, the compound layer starts to nucleate and grow. The initial condition for stage I can be described as

$$
t=0, \quad c=c_{0},
$$

where $c_{0}$ is the initial nitrogen concentration within grey cast iron.

The boundary condition for stage I is

$$
\begin{gathered}
x=\infty, \quad c=0, \quad x=0, \\
-D_{d} \frac{\partial c}{\partial x}=\beta\left(c_{g}-c_{s}\right),
\end{gathered}
$$

where $D_{d}$ represents the diffusion coefficient of atomic nitrogen in the diffusion zone, $x$ is the depth from surface, $c_{g}$ is the nitrogen concentration in the gas phase, and $c_{s}$ is the nitrogen concentration on the surface of grey cast iron.

At the end of stage I, the compound layer begins to be formed and the nitrogen concentration in the interface between compound layer and diffusion zone is in equilibrium. In the diffusing process, the nitrogen concentration in the interface is set as unchanged. Therefore, the obtained nitrogen concentration on the surface of cast iron can be considered as the initial boundary condition for stage II. Since the thickness of compound layer is much less than that of the diffusion zone [7], the influence of the interface moving during the nitriding process is ignored in the study. Based on the hypothesis, the boundary condition for stage II is of the following form:

$$
\begin{aligned}
& x=\infty, \quad c=0, \\
& x=0, \quad x=c_{d},
\end{aligned}
$$

where $c_{d}$ is the nitrogen concentration on the workpiece surface after stage I.

The parameters needed to be calibrated are the diffusion coefficient $D_{d}$ and mass transfer coefficient $\beta$. For parameter $D_{d}$, it is mainly influenced by the alloying element, which is capable of reacting with the atomic nitrogen. For grey cast iron, the governing alloying element is $\mathrm{Cr}$, whereas it has little effect on the diffusion coefficient when its content is lower than $5 \%[14,15]$. The $\mathrm{Cr}$ element in the analyzed grey cast iron is $0.051 \%$, so the influence can be ignored. The diffusion coefficient is determined by the following equation [16]:

$$
D_{d}=0.66 \exp \left(\frac{-77900}{R T}\right) \text {, }
$$

where $R$ is the gas constant with a value of $8.314 \mathrm{~J} / \mathrm{mol} \cdot \mathrm{K}$ and $T$ is the nitriding temperature.
TABLE 2: The tested hardness of the compound layer at 550, 570, and $590^{\circ} \mathrm{C}$.

\begin{tabular}{lccc}
\hline \multirow{2}{*}{ Distance from the surface $(\mu \mathrm{m})$} & \multicolumn{3}{c}{ Hardness value $(\mathrm{Hv})$} \\
& 550 & 570 & 590 \\
\hline 100 & 440 & 501 & 474 \\
130 & 403 & 455 & 447 \\
\hline
\end{tabular}

For parameter $\beta$, it is determined by the following equation [8]:

$$
\beta=0.0621 \exp \left(\frac{-6267}{T}\right)
$$

In practice, since the compound layer is a multiphase composition, the diffusion coefficient of atomic nitrogen in this area is hard to be determined, and the thickness of compound layer can only be determined by experimental data. Therefore, the study is aimed at predicting the thickness of diffusion zone and analyzing the influence of nitriding process parameters.

\section{Experimental Assessment}

4.1. Optical Microscope. The cross-sectional observation through optical microscopes was made. Figure 2 shows the case depths after nitriding at 550,570 , and $590^{\circ} \mathrm{C}$. As shown in the figure, the white layer is formed on the surface which is known as the compound layer. Beneath the compound layer, there is a diffusion zone, which is not so clear to be observed. It can be found that the compound layer increases with the increase in nitriding temperature, and the average thickness values at 550,570 , and $590^{\circ} \mathrm{C}$ are $4.50,9.05$, and $12.9 \mu \mathrm{m}$, respectively. The relationship between the compound layer thickness $(h)$ and nitriding temperature is plotted in Figure 3, which exhibits a linear characteristic; that is, $h=-110.9+$ $0.2 T$.

4.2. Hardness Measurement. The tested hardness values in the depth of 100 and $130 \mu \mathrm{m}$ are listed in Table 2. With the increase in distance from the surface, the hardness decreases to some degree. For both 100 and $130 \mu \mathrm{m}$, the hardness gets its maximum value at $570^{\circ} \mathrm{C}$.

The case depth is determined by testing the microhardness of the nitrided samples. The depth is considered to be the distance between the workpiece surface and the location where the hardness is the same with the matrix material. For the analyzed grey cast iron, the obtained average case depths after nitriding are 79,139 , and $155 \mu \mathrm{m}$ at 550,570 , and $590^{\circ} \mathrm{C}$, respectively.

4.3. XRD Analysis. Figure 4 presents the XRD diffractogram of the sample's surface. The horizontal and longitudinal coordinate represents the diffractogram angle and diffractogram 


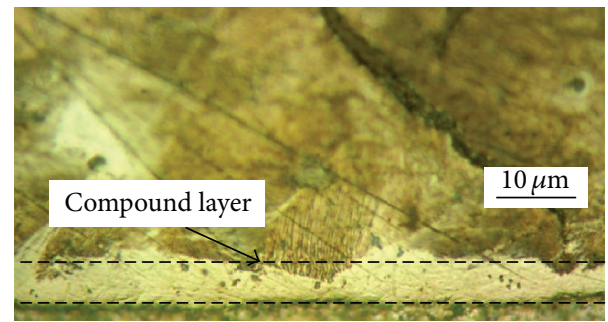

(a)

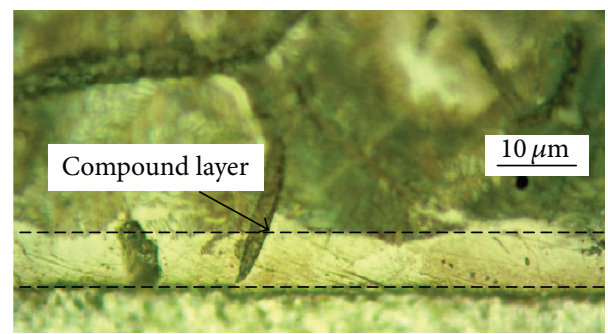

(b)

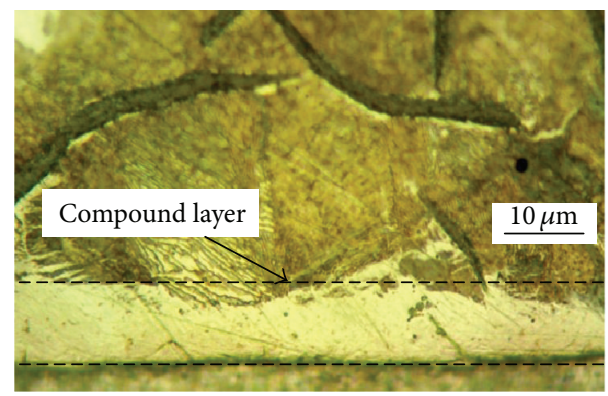

(c)

FIGURE 2: Cross-sectional scanning electron microscopy observation of the nitrided samples at (a) 550 , (b) 570 , and (c) $590^{\circ} \mathrm{C}$.

strength, respectively. Due to the relative thinness of the compound layer, the reflection intensity of the $\gamma^{\prime}-\mathrm{Fe}_{4} \mathrm{~N}$ phase is not distinct enough. Nevertheless, it can be found that after nitriding, the major phases on the surface are $\gamma^{\prime}-\mathrm{Fe}_{4} \mathrm{~N}$ and $\varepsilon$ $\mathrm{Fe}_{3} \mathrm{~N}$, which confirms the presence of superficial compound layer.

\section{Numerical Results and Discussions}

5.1. Numerical Results. The gas nitriding process in the study was simulated by using the model described in Section 3 . The calculated nitrogen concentration of grey cast iron is depicted in Figure 5. It can be seen that with the increase in nitriding temperature, the thickness of diffusion zone increases. For a clear presentation, the experimental and calculated thickness values are listed in Table 3 and the calculation errors are also presented. It needs to be noted that the tested thickness of diffusion zone is determined by removing the compound layer from the tested case depth. The calculated thickness values are in good agreement with the experimental data, with an absolute maximal error value of $6.8 \%$, which demonstrates the accuracy and feasibility of the numerical simulations.

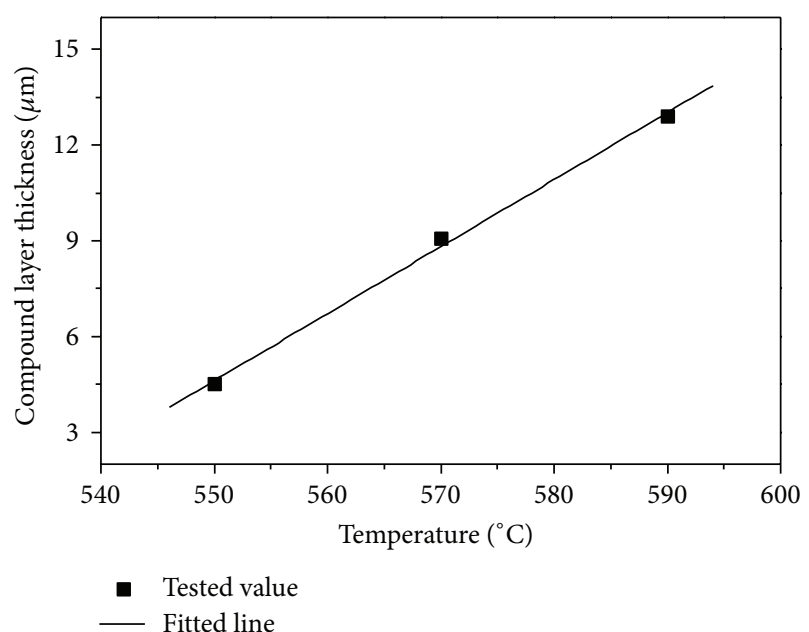

FIGURE 3: Experimental compound layer thickness as a function of nitriding temperature.

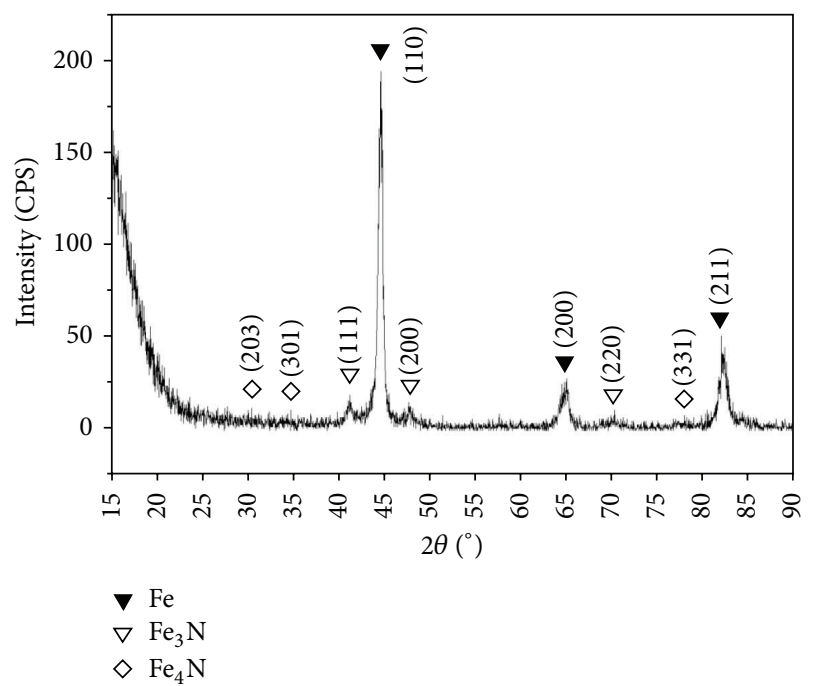

FIGURE 4: XRD diffractogram of the sample's surface for the analyzed grey cast iron after nitriding.

TABLE 3: The calculated and experimental case depths of the grey cast iron at 550,570 , and $590^{\circ} \mathrm{C}$.

\begin{tabular}{lccc}
\hline$T\left({ }^{\circ} \mathrm{C}\right)$ & Tested $(\mu \mathrm{m})$ & Calculated $(\mu \mathrm{m})$ & Error $(\%)$ \\
\hline 550 & 74 & 79 & 6.8 \\
570 & 129 & 125 & -3.1 \\
590 & 142 & 141 & -0.7 \\
\hline
\end{tabular}

For the presence of calculation error, it can be attributed to the following reasons. Firstly, during calculation, the influence of the interface's movement was not considered, which was a disadvantage of the present model. Secondly, the critical value of nitrogen potential, which was directly obtained from the Lehrer diagram of pure iron, may not be accurate for grey cast iron. Furthermore, for the analyzed grey cast iron, the largely distributed graphite may also have some uncertain effects on the nitriding potential value. 


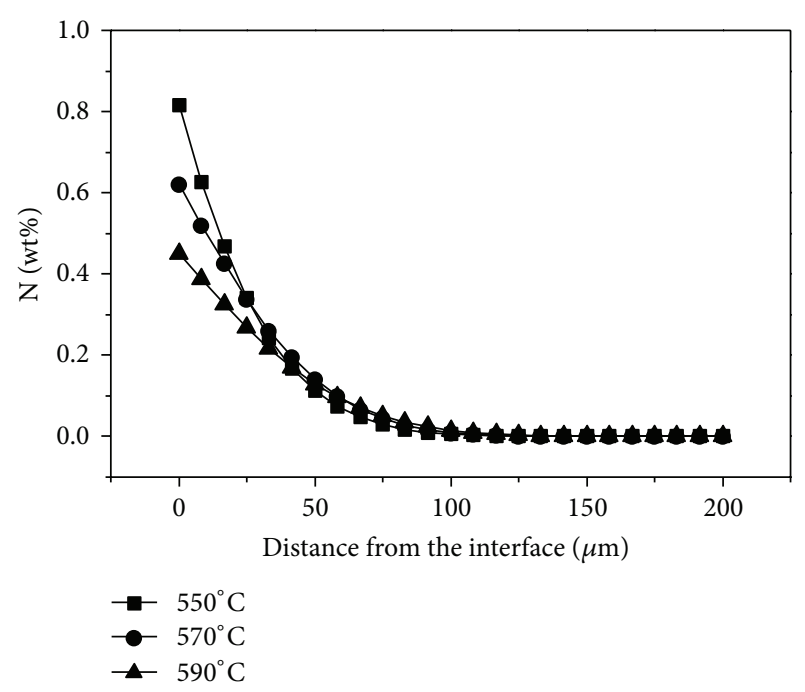

FIGURE 5: The calculated nitrogen concentration distribution at 550, 570 , and $590^{\circ} \mathrm{C}$.

Nevertheless, the accuracy of the numerical simulations is considered to be acceptable, which is a guarantee of the following effect analysis of nitriding process parameters.

5.2. Effect of Nitriding Temperature on the Threshold Value of Nitriding Potential. Nitriding temperature is a crucial process parameter which greatly affects the gas nitriding process. In the study, a threshold value of nitrogen potential is adopted instead of the traditional critical value, which is a significant advantage of the present model in comparison with the existing ones [5-7]. The relationship between the threshold value and temperature is given in Figure 6. As temperature increases, the threshold value decreases significantly. Under the circumstances, the time needed to form the compound layer decreases at higher nitriding temperature.

5.3. Effect of Nitriding Potential. Nitrogen potential, which represents the nitrogen activity on the workpiece surface, is used to control the compound layer's thickness and phases. In order to investigate the influence of nitrogen potential, numerical simulations were conducted with respect to different nitriding potential values, that is, $0.32,0.75,1.5$, and $3.5 \mathrm{~atm}^{-1 / 2}$. Figure 7 presents the calculated nitrogen concentration profile for different nitriding potentials. It can be observed that the nitrogen potential has no effect on the case depth. However, the nitrogen concentration on the workpiece surface is of great difference, which exhibits the highest value for nitriding potential of $3.5 \mathrm{~atm}^{-1 / 2}$. The analysis results directly demonstrate that the nitriding potential has great effect on the phase composition of compound layer, since it strongly influences the nitrogen concentration on the surface.

5.4. Effect of Nitriding Time. To investigate the influence of nitriding time on the case depth, numerical calculations were performed with different nitriding time of $7,11,24$, and 40 hours. Figure 8 shows the calculated nitrogen concentration

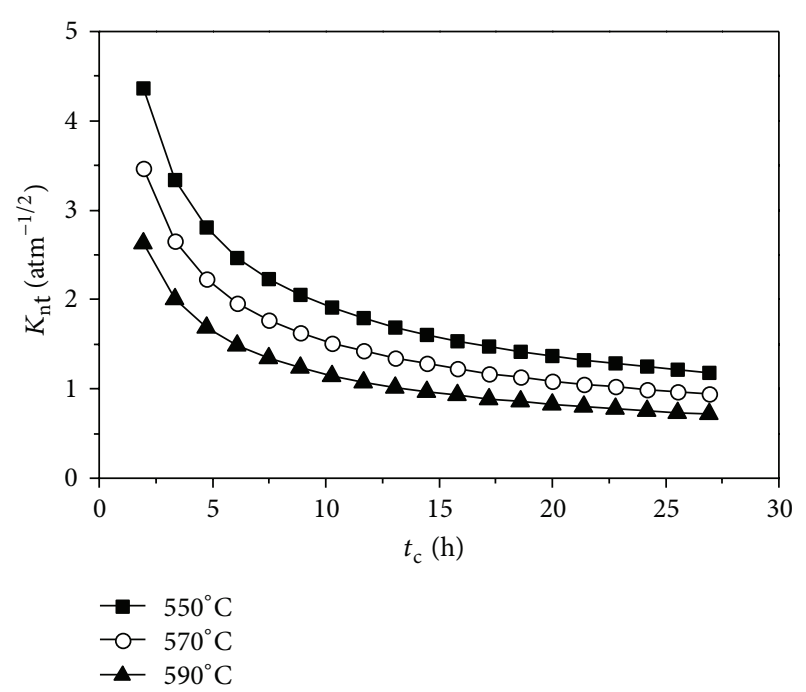

FIGURE 6: The threshold value of nitrogen potential at different temperatures.

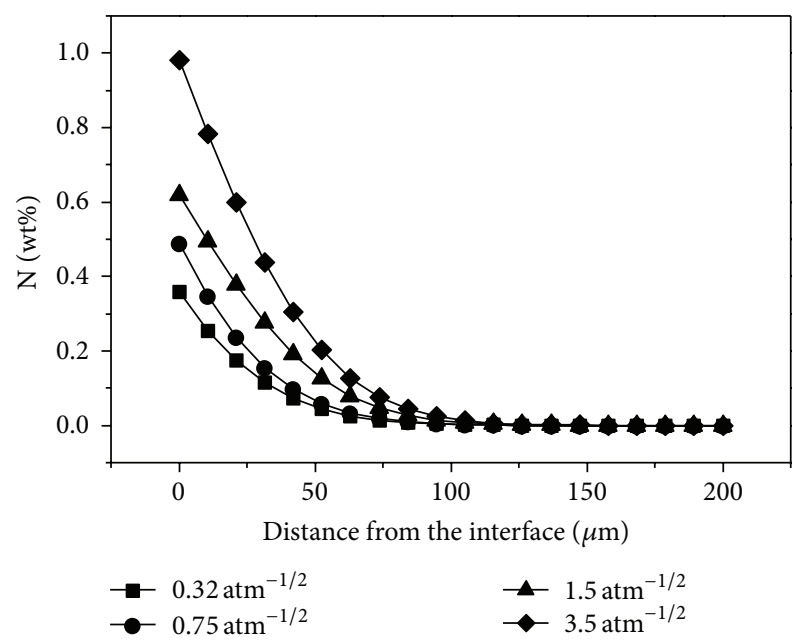

FIGURE 7: The nitrogen concentration distributions with different nitriding potentials.

profile for different nitriding time. Because the threshold values of nitriding potential at the nitriding time of 7 and 11 hours are higher than those of the present nitriding potential, no compound layer is formed on the surface. When nitriding time is 24 and 40 hours, the compound layer is formed and the nitrogen concentration on the workpiece surface turned into the same value. At the same time, the case depth increases as nitriding time increases from 24 to 40 hours.

\section{Conclusions}

Based on the gas nitriding experiments and numerical simulations, the following conclusions can be drawn.

(1) The numerical simulations, taking into account the influence of threshold value of nitriding potential, can 


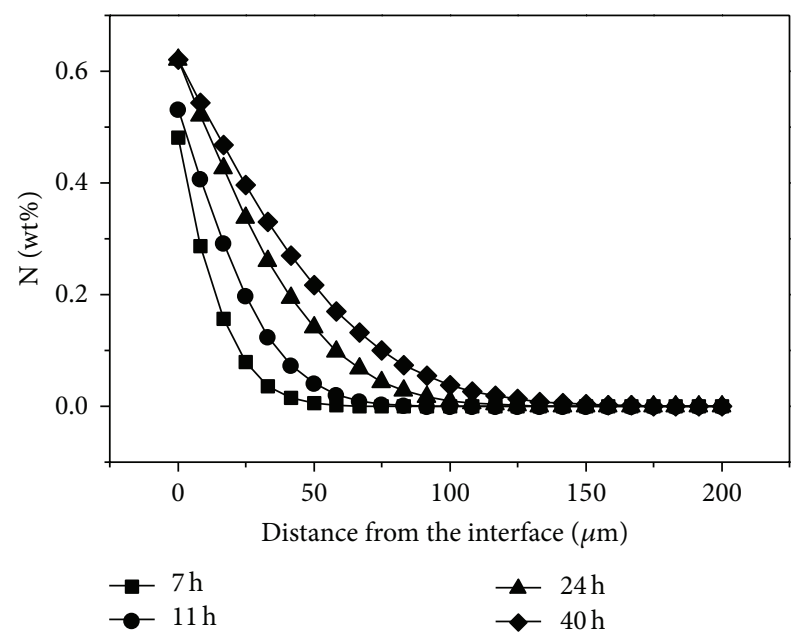

FIGURE 8: The nitrogen concentration distributions with different nitriding time.

precisely predict the thickness of diffusion zone and nitrogen concentration profile.

(2) With the increase in nitriding temperature and time, the thickness of case depth increases to some degree, whereas the nitrogen concentration on the surface decreases as nitriding temperature increases.

(3) For the analyzed grey cast iron, the nitriding potential has little effect on the thickness of case depth but has a relatively great influence on the nitrogen concentration of workpiece surface and composition of nitriding layer. The proposed numerical simulations for nitriding layer prediction and analysis can be a reference for practical engineering applications.

\section{References}

[1] M. A. J. Somers, "Thermodynamics, kinetics and microstructural evolution of the compound layer; A comparison of the states of knowledge of nitriding and imitrocarburising," Heat Treatment of Metals, vol. 27, no. 4, pp. 92-102, 2000.

[2] D. Pye, Practical Nitriding and Ferritic Nitrocarburizing, Materials Park, Ohio, Ohio, USA, 2003.

[3] M. A. J. Somers and E. J. Mittemeijer, "Layer-growth kinetics on gaseous nitriding of pure iron: evaluation of diffusion coefficients for nitrogen in iron nitrides," Metallurgical and Materials Transactions A, vol. 26, no. 1, pp. 57-74, 1995.

[4] H. Du, M. A. J. Somers, and J. Agren, "Microstructural and compositional evolution of compound layers during gaseous nitrocarburizing," Metallurgical and Materials Transactions A, vol. 31, no. 1, pp. 195-211, 2000.

[5] A. F. M. Arif, S. S. Akhtar, and B. S. Yilbas, "Effect of process variables on gas nitriding of $\mathrm{H} 13$ tool steel with controlled nitriding potential," International Journal of Surface Science and Engineering, vol. 4, no. 4-6, pp. 396-415, 2010.

[6] M. Yang and R. D. J. Sisson, "Modeling the nitriding process of steels," Advanced Materials and Processes, vol. 170, no. 7, pp. 3336, 2012.

[7] M. Yang, C. Zimmerman, D. Donahue, and J. R. D. Sisson, "Modeling the gas nitriding process of low alloy steels," Journal of Materials Engineering and Performance, vol. 22, no. 7, pp. 1892-1898, 2013.

[8] M. J. Hu, J. S. Pan, and Y. J. Li, "Mathematical modelling and computer simulation of nitriding," Materials Science and Technology, vol. 15, no. 6, pp. 547-550, 2000.

[9] M. J. Hu and J. S. Pan, Fundamentals of Thermochemical Surface Treatment of Steel, Shanghai Jiao Tong University Press, Shanghai, China, 1996.

[10] W. D. Jentzsch, F. Esser, and S. Boehmer, "Mathematical model for the nitriding of soft iron by ammonia-hydrogen mixtures," Neue Hutte, vol. 26, no. 1, pp. 19-23, 1981.

[11] Z. X. Zhu and K. F. Yao, Engineering Materials, Tsinghua University Press, Beijing, China, 2011.

[12] L. S. Darken and R. W. Gurry, Physical Chemistry of Metals Istedition London, McGraw-Hiu, 1953.

[13] T. Bell, "Controlled nitriding in ammoniahydrogen mixturs," Heat Treatment, vol. 73, pp. 51-57, 1975.

[14] Y. Sun and T. Bell, "A numerical model of plasma nitriding of low alloy steels," Materials Science and Engineering A, vol. 224, no. 1-2, pp. 33-47, 1997.

[15] T. Spalvins, "Tribological and microstructural characteristics of ion-nitrided steels," Thin Solid Films, vol. 108, no. 2, pp. 157-163, 1983.

[16] L. Torchane, P. Bilger, J. Dulcy, and M. Gantois, "Control of iron nitride layers growth kinetics in the binary Fe-N system," Metallurgical and Materials Transactions A, vol. 27, no. 7, pp. 1823-1835, 1996. 

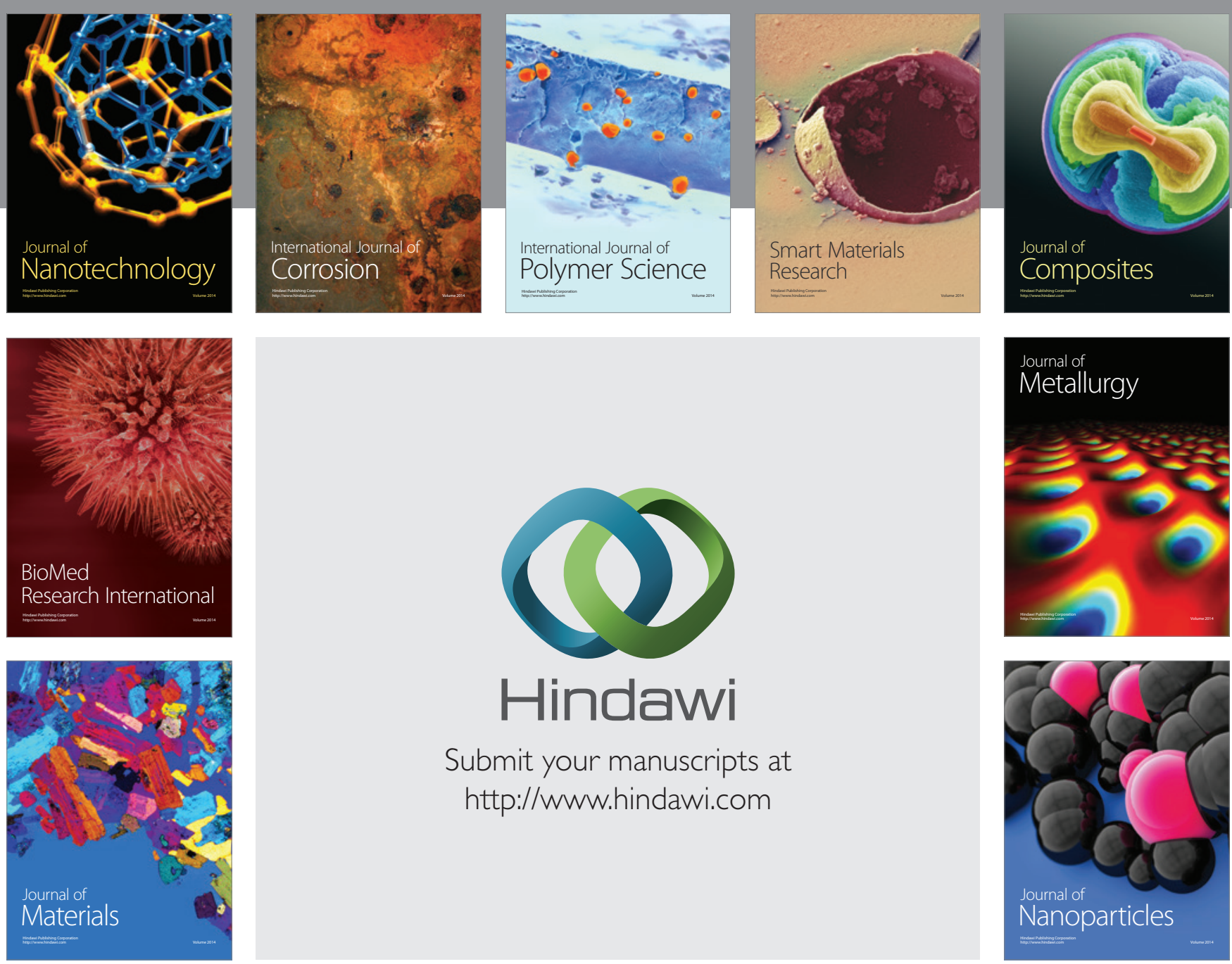

Submit your manuscripts at http://www.hindawi.com
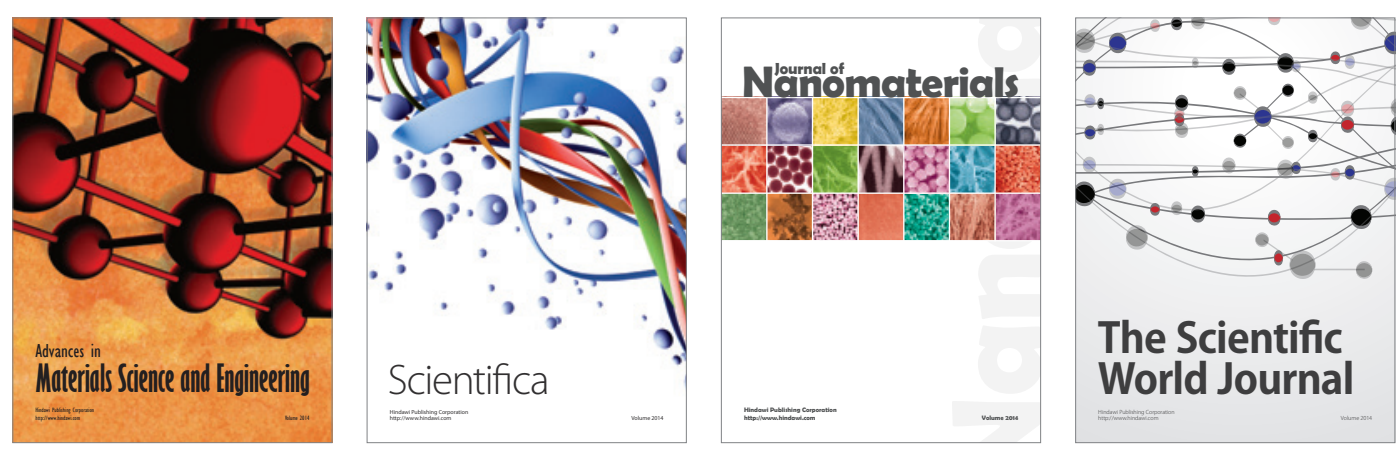

\section{The Scientific World Journal}
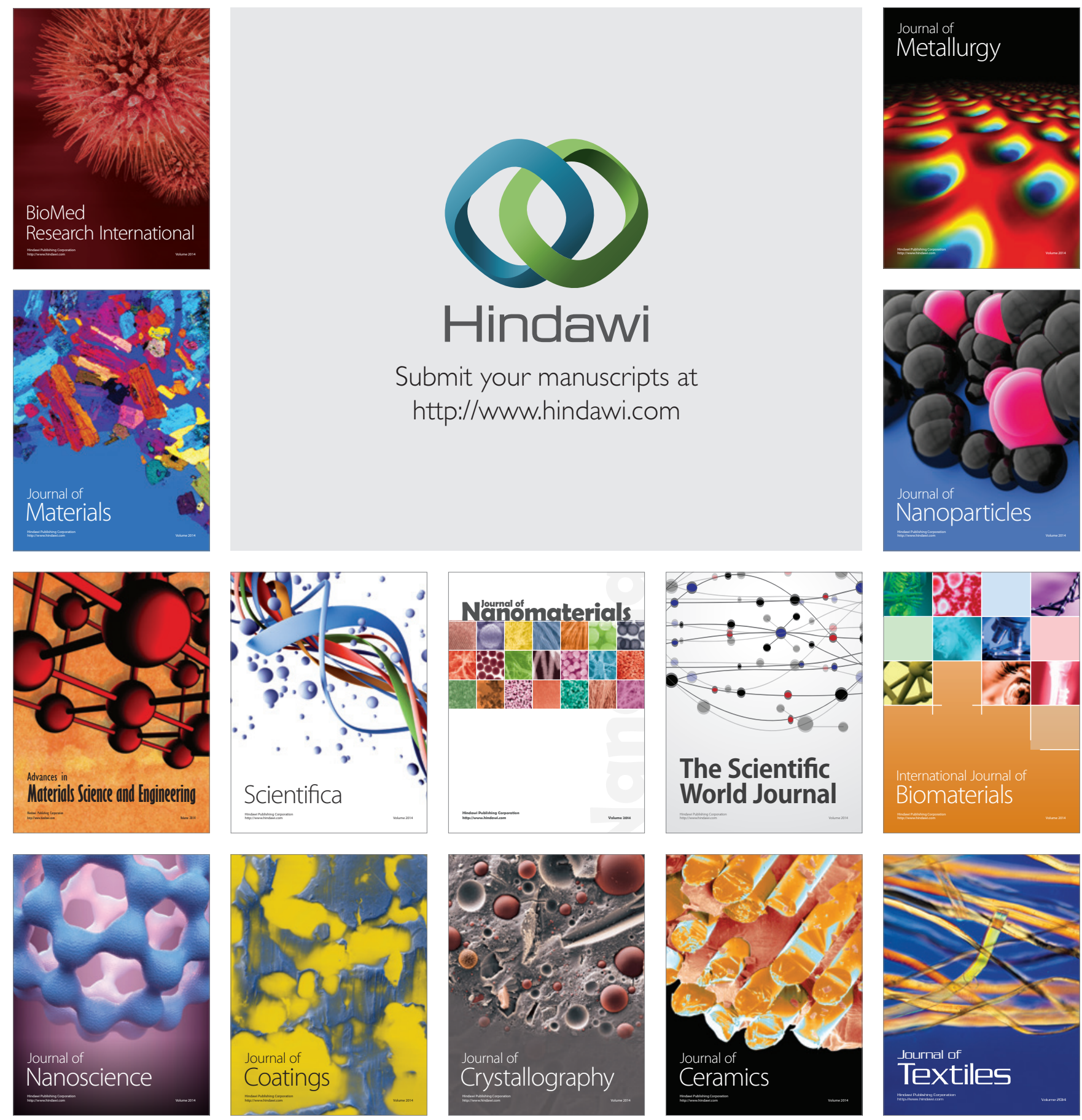